\title{
PENGOLAHAN SAMPAH ORGANIK DENGAN METODE TAKAKURA DI SMK PPM AL-IKHLAS POLMAN
}

\author{
Nurgadima Achmad Djalaluddin 1 Muh Fauzar Al-Hijrah ${ }^{2}$ Heriyati*3 $^{*}$ Masniati $^{4}$ \\ 1,2,3,4 Universitas Sulawesi Barat \\ 1,2,3,4 Administrasi Kesehatan, Fakultas Ilmu Kesehatan, Universitas Sulawesi Barat \\ *e-mail: heriyati@unsulbar.ac.id
}

\begin{abstract}
Garbage is a crucial problem to date, every day there are tons of waste produced by humans and most of it is household waste. Much waste is generated from factories, plastic waste and household waste such as food scraps and scraps of vegetable and fruit waste so more effective and environmentally friendly countermeasures are needed. The takakura method is an option and innovation that is one of the solutions that can be used and can even be of economic value. The purpose of this community service is so that students can find out how to make organic fertilizer using household / kitchen waste and producing household / kitchen waste using the Takakura method. The partner of this community service is Al Ikhlas Vocational School boarding school. The service method used is to provide counseling about waste and then practice how to process organic waste into fertilizer using the Takakura method. The results obtained in this service produced organic waste fertilizer which is processed for one month and is ready to use and economical.
\end{abstract}

Keywords: garbage, organic, takakura method

\begin{abstract}
Abstrak
Sampah merupakan masalah yang krusial sampai saat ini, setiap harinya ada berton-ton sampah yang dihasilkan manusia dan sebagian besar merupakan sampah rumah tangga. Sampah yang sangat banyak dilahirkan dari pabrik, sampah plastik dan limbah rumah tangga seperti sisa makanan dan dan potongan sisa sayur dan buah sehingga dibutuhkan penanggulangan yang lebih efektif dan ramah terhadap lingkungan. Dengan metode takakura ini merupakan suatu opsi dan inovasi yang menjadi salah satu solusi yang bisa digunakan bahkan dapat bernilai ekonomis. Tujuan pengabdian masyarakat ini Agar siswa dapat mengetahui cara pembuatan pupuk organik dengan menggunakan limbah rumah tangga/dapur dan memproduksi sampah limbah rumah tangga/dapur dengan metode takakura. Mitra dari pengabdian masyarakat ini adalah pesantren SMK PPM Al Ikhlas. Metode Pengabdian yang dilakukan adalah dengan memberikan penyuluhan tentang sampah kemudian praktek cara pengolahan sampah organik menjadi pupuk dengan metode takakura. Hasil yang diperoleh pada pengabdian ini dihasilkan pupuk sampah organik yang diproses selama satu bulan dan siap pakai serta ekonomis.
\end{abstract}

Kata kunci: sampah, organik, metode takakura

\section{PENDAHULUAN}

Sampah adalah salah satu masalah yang melekat terhadap negara berkembang seperti, india, tahiland, indonesia dan lain-lain. Program Adipura dilaksanakan setiap tahun sejak 1986. Namun, pada tahun 1998 program ini sempat terhenti dan baru dilaksanakan kembali pada tahun 2002. Melalui Penghargaan Adipura, program kerja Kementerian LHK ini bertujuan mendorong kepemimpinan kabupaten/kota dalam membangun partisipasi aktif masyarakat serta dunia usaha untuk mewujudkan kota yang berkelanjutan, baik secara ekologis, sosial, dan ekonomi (Kementrian LHK, 2017)

Menurut Munas Dwiyanto (2011) Pengelolaan sampah berbasis masyarakat adalah upaya penanganan sampah yang melibatkan partisipasi aktif dari masyarakat untuk mengelola sampah mulai dari tahap penimbunan, pengumpulan, pengolahan hingga pemrosesan akhir. Dalam pengelolaan sampah, peran masyarakat menjadi penting karena 
Masyarakat seharusnya bisa mandiri dalam pengelolaan sampah untuk mendukung terciptanya sistem pengelolaan sampah berkelanjutan

Salah satu contoh pengabdian masyarakat di Pondok Pesantren As-Salamah, berada di wilayah desa pantai yang sangat kental dengan kondisi lingkungan yang memprihatinkan. Sampah bertebaran di mana-mana, sungai yang mengalami pendangkalan karena sampah, sistem sanitasi yang belum terkelola secara terprogram merupakan gambaran umum di desa pantai. Sebagai sebuah lembaga yang berada di wilayah pantai, maka Pondok Pesantren Putri As-Salamah menjadi gambaran mikro dari kondisi komunitas pantai tersebut. Kondisi kebersihan dan kerapihan di dalam pondok pesantren yang kurang tampak, pemakaian plastik yang tinggi, kurang terbiasanya menggunakan peralatan yang bertahan lama, tempat sampah yang kurang memadai, serta model pembuangan sampah yang kurang ramah lingkungan merupakan gambaran umum dari lingkungan yang ada di pesantren (Elizabeth, 2017)

Hasil observasi yang dilakukan di pesantren PPM Al-Iklhas menunjukkan bahwa sampah organik yang telah dipakai ataupun sisa sayuran yang tidak digunakan akan dibuang di tempat sampah begitu saja. Sehinggah lingkungan area dapur pesantren menjadi sangat kotor dengan tumpukan sampah organik. Adapun sampah-sampah sisa makanan akan langsung terbuang ke saluran air dapur yang mengarah ke kolam ikan pesantren. Oleh karena itu untuk meminimalisis sampah organik yang sudah tidak dipakai lagi maka perlu membuat suatu tindakan pengelolaan sampah organik yang ramah lingkungan dan ekonomis.

Tujuan pengabdian ini adalah untuk memberdayakan masyarakat khususnya rumah tannga sehingga mereka mampu dan mandiri dalam hal siswa/i dapat mengetahui cara pembuatan pupuk organik ( metode takakura) yang ekonomis dan mudah dan dapat memproduksi sampah limbah dapur maupun rumput dengan metode takakura secara mandiri.

\section{METODE}

Metode yang digunakan untuk menyelesaikan masalah yaitu pemberian Pelatihan diberikan kepada siswa kelas X SMK PPM AL-IKHLASH. Dari 10 siswa akan dibagi menjadi 2 kelompok sehingga tiap-tiap kelompok terdiri dari 5 siswa. Masing-masing kelompok akan didampingi oleh 1 orang dosen. Setiap kelompok akan diberikan bahan dan alat yang dibutuhkan dalam proses pembuatan kompos. Pemaparan tentang pembuatan kompos dengan EM 4 yang disampaikan oleh salah satu dosen. Selanjutnya pembagian alat dan bahan yang akan dikoordinatori oleh masing-masing 1 dosen. Masing-masing kelompok bersama satu orang pendamping dosen akan bersama membuat kompos hingga siap simpan. Kegiatan diselenggarakan dengan langkah-langkah yang sudah ditetapkan, meliputi persiapan alat-alat prkatik, pelaksanaan kegiatan, evaluasi, dan laporan hasil kegiatan. Jenis kegiatan yang dilakukan adalah penyuluhan berkenaan dengan daur ulang sampah organik, di SMK PPM AL-IKHAS Polman. Materi diberikan oleh tim pelaksana Pengabdian Pada Masyarakat dengan metode ceramah, simulasi, diskusi serta praktek.

\section{HASIL DAN PEMBAHASAN $\leftarrow$ Arial, Bold, 11 pt}

Tim Pengabdian masyarakat menjelaskan secara rinci perbedaan sampah organik dan non organik. Sampah organik merupakan sampah sisa yang masih bisa dimanfaatkan menjadi bahan yang layak pakai lagi. Sampah ini bisa diuraikan, meski dibiarkan begitu saja sampah ini akan menghilang dengan sendirinya. Banyak contoh ini seperti sisa makanan, kulit buah, sisa masakan dari dapur dan lain sebagainya. 
Pemanfaatannya bisa dijadikan sebagai pakan ternak, biogas, atau lain sebagainya. Sampah non organik merupakan sampah yang sudah dibuang dan tidak layak lagi dipakai. Sampah ini tidak bisa terurai contohnya seperti plastik, kresek, botol minuman, ember dan lain sebagainya. Meski sampah ini tidak bisa terurai, tapi pemanfaatannya bisa dikomersilkan untuk diolah kembali menjadi barang yang layak pakai (Kompas, 2015)

Keranjang kompos Takakura merupakan satu metode pengomposan hasil penelitian seorang ahli bernama Mr. Koji Takakura dari Jepang. Pada awalnya Mr. Takakura melakukan penelitian di Surabaya untuk mencari sistem pengolahan sampah organik yang cocok selama kurang lebih setahun. Proses pengomposan ala keranjang takakura merupakan proses pengomposan aerob, dimana udara dibutuhkan sebagai asupan penting dalam proses pertumbuhan mikroorganisme yang menguraikan sampah menjadi kompos (Kurniati, 2013).

Agar mempercepat proses berlangsungnya pengomposan diperlukan aktivator/ bioaktivator, pada umumnya dicampurkan secara langsung pada saat pengadukan bahan bahan baku yang akan didekomposisi. Istilah bioaktivator dimaksud sebagai isolat mikroba yang telah dimurnikan dan mempunyai kemampuan khusus dalam mencerna bahan oraganik yang mengandung serat selulosa. Bioaktivator yang umum dan biasa digunakan diantaranya EM-4 maupun effectif microorganism 4 yang ditemukan oleh Prof. Teruo Higa. Bioaktivator EM- 4 dapat lebih efektif mempercepat proses pengomposan dan juga mencegah timbulnya bau selama proses komposting. Adapun bahan organik yang dapat dikomposkan dengan EM-4 antara lain jerami, serbuk gergaji, pupuk kandang, kotoran hewan, rumput sekam atau serbuk gergaji. (Mc Safley, 1992; Pace, Miller, \& FarrelPoe, 1995; Misra, Roy, \& Hiraoka, 2003).

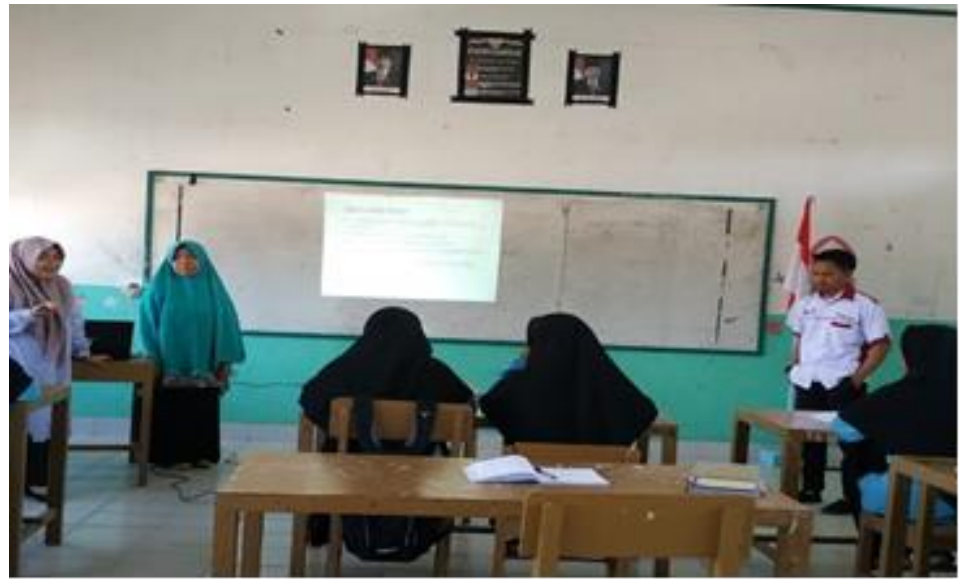

Gambar 1. Penjelasan Mengenai Metode Takakura

Gambar 1 merupakan Pemaparan tentang pembuatan kompos, hal apa saja yang perlu dipersiapkan, terkait alat dan bahan serta tata cara pengomposan. 


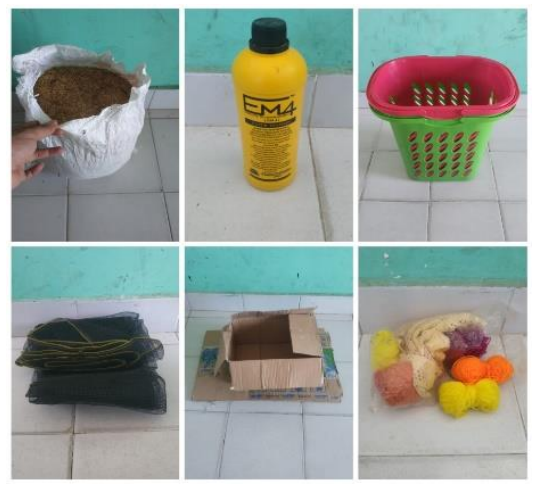

Gambar 2 Alat dan Bahan

Penyediaan alat dan bahan meliputi Keranjang takakura (bertutup), Kardus, Tali rafia, Gunting/cutter, Kain berpori, Garu kecil atau sejenisnya, Benang Jarum , Sekam/dedak/serbuk gergaji, EM4 / mikroorganisme.

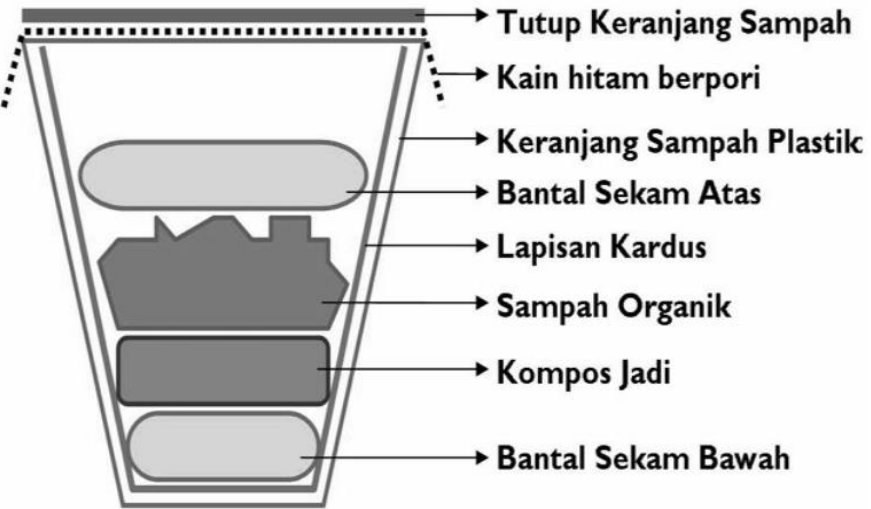

Gambar 3. Susunan Komponen Keranjang Takakura
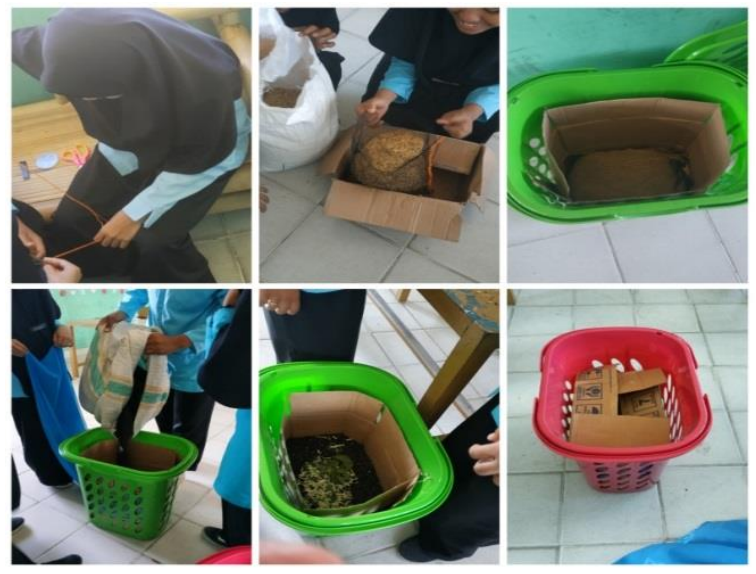

Gambar 4 Proses Pembuatan

Gambar 3 dan 4 menunjukkan bentutk susunan komponen keranjang Takakura dan cara pembuatan yaitu siapkan keranjang Sampah yang berpori-pori atau berlubang kecil-kecil pada dindingnya dengan ukuran sedang Lapisi bagian dalam setiap keranjang dengan kardus bekas kering kemudian diikat dengan tali agart kardus tidak mudah bergeser. Masukan bantal sekam pertama yang telah terbuat dri serbuk gergaji pada dasar keranjang. Masukan 1/4 starter (sekam bakar yang telah disemprotkan EM4) kedalam keranjang Takakura Potong/cacah sampah organik $2-4 \mathrm{~cm}$ seperti sayur mayur yang tidak digunakan atau kulitdari buah apel, pisang, pepaya dan lain-lain. Masukan sampah organik yang telah dicacah tersebut kedalam keranjang takakura sedikitdemi sedikit. Aduk sampah organik dengan starter sampai merata. Agar memastikan kompos berjalan dengan baik, letakkan tangan $\pm 2 \mathrm{~cm}$ dari kompos. Jika terasa hangat maka pengomposan bekerja dengan baik. Semprotkan sedikit EM4 secara merata diatas permukaan campuran sampah organik dan starter Tutup campuran kompos dengan bantalan sekam dan kain berpori. Tutup dengan penutup keranjang. Jika ingin menambahkan sampah organik keesokan harinya agar memperhatikan volume sampah tidak terlalu banyak karena wadah yang digunakan tidak terlalu besar Ulangi kegiatan tersebut sampai 30 hari. 
Evaluasi kegiatan dengan Mengevaluasi tiap minggu selama satu bulan hasil dari adonan takakura yang telah dibuat, dengan mengecek sampah yang telah dimasukkan tetap terjaga kelembapannya dan tidak terdapat beatungtaupun berjamur. Jika belatung berarti sampah organik yang dimasukkan ke dalam campuran tdk memperhatikkan kebersihannya dan jika berjamur berrti kelembapannya tidak terjaga dengan baik, mungkin saja sampah organik basah pada saat dicampurkan.

Hasil evaluasi menunjukkan dua keranjang takakura berproses dengan baik dengan tetap terjaga kelembapannya, tidak berbelatung maupun berjamur sehingga kompos organik bisa di panen. Panen kompos organik takakura harus memperhatikan jumlah yang disisahkan dalam wadah takakura agar pengomposan tetap bisa berlanjut tanpa harus mengulang dari tahap awal lagi.

Setelah kompos takakura dipanen, Tim pengabdian masyarakat membuka sesi diskusi terhadap siswa mengenai sampah dan kegiatan pengomposan dengan metode takakura yang telah kita buat bersama-sama. hasil diskusi tim dengan siswa dapat disimpulkan bahwa adanya peningkatan pengetahuan dan kesadaran para siswa akan pengolahan sampah organik yang ada di lingkungan sekitar mereka menjadi kompos ramah lingkungan. Selain ramah lingkungan kompos ini juga bisa bernilai ekonomis jika dipermak dengan baik dan di komersilkan untuk membuka jiwa intrepreneurship para siswa

\section{KESIMPULAN}

Dalam pelatihan pembuatan kompos memberdayakan masyarakat khususnya rumah tannga sehingga mereka mampu dan mandiri dalam hal. Siswa dan siswi mengetahui cara pembuatan pupuk organik ( metode takakura) yang ekonomis dan mudah. Siswa dapat memproduksi sampah limbah dapur maupun rumput dengan metode takakura secara mandiri. Sehingga para siswa dapat lebih peduli terhadap lingkungan sekitarnya.

\section{DAFTAR PUSTAKA}

Anonim. Perbedaan Sampah Organik dan Sampah Non Organik diakses dari https://www.kompasiana.com/pgalih/54f39bad745513802b6c7bf7/perbedaan-sampah-organikdan-sampah-non-organik padatanggal 4 februari tahun 2020

Damanhuri, E dan Padmi, T. 2003. Diktat Kuliah Pengelolaan Sampah. Institut Teknologi Bandung, Bandung.

Elizabeth, Misbah Zulfa. 2017. Program Pengelolaan Kebersihan Lingkungan di Pesantren. DIMAS Volume 17, Nomor 1

Kementrian Lingkungan Hidup dan Hutan. 2017. Statistik lingkungan hidup Indonesia. Jakarta

Kurniati, S.W. 2013. Pembuatan Kompos Skala Rumah Tangga Sebagai Satu Upaya Penanganan Masalah Sampah di Kota Mataram. Media Bina Ilmiah.Vol 7; no. 1, p.23-27.

Mc Safley, L. M., Dupoldt,C.,Geler,F.,StettlerD., \& Murphy,T. (1992). Agricultural waste management system component design. In: Krider, J. N. \& Rickman, J. D. (Eds). AgriculturalWaste Management Field Handbook (pp. 1-85).UnitedStates: Soil Conservation Service.

Misra, R. V., Roy, R. N., \& Hiraoka, H. (2003). On farmcomposting methods. Rome: FAO.

Munas Dwiyanto, Bambang. 2011. Model Peningkatan Partisispasi Masyarakat dan Penguatan Sinergi dalam Pengelolaan Sampah Perkotaan. Jurnal Ekonomi Pembangunan. Vol 12 No 2 Desember 2011: 239-256.

Rini Indriyanti, Dyah., Banowati, Eva., \& Margunani. 2015. Pengolahan Limbah Organik Sampah 
Pasar Menjadi Kompos. ABDIMAS Vol. 19 No. 1. Semarang

Rosalina Y. Kurang, Efrin A. Dollu, \& Isak F. Alelang. (2020). PELATIHAN PEMBUATAN HAND SANITIZER DARI BAHAN ALAMI DI DESA OTVAI. Jurnal Abdimas Bina Bangsa, 1(1), 137-142. doi:10.46306/jabb.v1i1.49

Vivien Novarina A. Kasim, \& Nirwanto K. Rahim. (2020). PEMBERDAYAAN LINGKUNGAN PADA MASYARAKAT SADAR GIZI UNTUK KETAHANAN PANGAN DESA. Jurnal Abdimas Bina Bangsa, 1(2), 257-266. doi:10.46306/jabb.v1i2.46 